Check for updates

1 Cochrane Sustainable Healthcare

2 The BMJ

3 Institute for Evidence-Based Healthcare at Bond University

Cite this as: BMJ 2021;375:n2758 http://dx.doi.org/10.1136/bmj.n2758

Published: 15 November 2021

\section{The Recovery-a podcast about action for sustainable healthcare}

\author{
Cochrane Sustainable Healthcare and The BMJ are launching a pop-up podcast series, featuring \\ conversations with people finding new and sometimes radical approaches to wind back medical \\ excess and make health systems healthier in the long run
}

Minna Johansson, ${ }^{1}$ Fiona Godlee, ${ }^{2}$ Ray Moynihan ${ }^{3}$

The way we currently practice medicine is unsustainable for patients, healthcare systems, societies, and the planet. It is estimated that a fifth of what we do in healthcare is not needed. ${ }^{1}$ All those unnecessary tests, treatments, and diagnoses bring direct harm to people through adverse effects of drugs and surgeries, ${ }^{2}$ psychosocial harms of labelling, ${ }^{3}$ and increasing the burden of treatments. ${ }^{4}$ Since resources for healthcare are finite, waste is also harming patients indirectly because the overuse of some medical interventions means there are fewer resources to tackle underuse and underdiagnosis in other areas. ${ }^{5}$ Moreover, when healthcare spending grows, as it is doing everywhere, ${ }^{1}$ resources are drawn from other societal sectors which can improve public health far more effectively than interventions within healthcare ${ }^{6}$ Considering the substantial carbon footprint from health systems themselves, medical waste also increases harm to the planet. ${ }^{7}$

The drivers of unsustainable healthcare are complex and diverse, and solutions should be guided by reliable and robust evidence which is built based on considerations of equity. ${ }^{8}$ The related crises of climate change and medical excess mean our evidence ecosystem needs to adapt to support more sustainable decision-making within healthcare. We urgently need to find out how to efficiently and safely wind back the tests, treatments, and diagnoses causing people more harm than good. Doing this will produce a win-win by also helping our transformation to a de-carbonised healthcare system.

To help promote this transformation The BMJ has joined forces with Cochrane Sustainable Healthcare ${ }^{9}$ to launch a new podcast called The Recovery. It will feature compelling and inspirational conversations with those actively working to wind back medical excess and forge a more sustainable healthcare system. From Mumbai to Minnesota, you will hear about new, and sometimes radical, initiatives that are changing the way doctors practice medicine, to ensure better access to high quality, evidence-based, and safe healthcare.

We will meet Australian doctors Rachelle Buchbinder and Ian Harris, who are fearlessly challenging professional norms and creating new structures to wind back ineffective and dangerous care in medicine and surgery. From India, there is a conversation with CS Pramesh, the high-profile cancer specialist helping lead Choosing Wisely's efforts to reduce wasteful care in low- and middle-income countries. We'll hear from Victor Montori, the Peruvian-born Mayo Clinic-based doctor who is inciting a non-violent revolution of careful and kind care, and of unhurried conversations with patients built on compassion and solidarity.

One of the podcast's gems is an interview with Gillian Orrow, a Cambridge University trained general practitioner testing a novel and radical approach to improving the health and wellbeing of the population she serves. Along with colleagues, she is attacking the social determinants of ill health, while helping build a community and de-emphasising over-medicalisation. Another highlight in The Recovery podcast series is Leonore Tiefer, whose successful global campaign to slow the medicalisation of common female sexual problems is a model for community action against overdiagnosis and overtreatment. Hope and inspiration flows too through the conversation with Renee Salas, the Harvard-based Emergency doctor who has testified to US Congress about the urgency of addressing climate change, and who is transforming what it means to be a medical doctor.

All these voices are part of a growing global chorus campaigning for fundamental reform of how we practise medicine and showing that radical new alternatives are feasible. At the coalface, patients and clinicians still face a tsunami of recommendations to do more tests and treatments, with no possibility to follow more than a tiny fraction of them. ${ }^{410}$ We must start appreciating that patients' and clinicians' time is a finite resource that should be carefully prioritised. Spending on healthcare should be prioritised in relation to societal strategies to improve the health and wellbeing of the population, to ensure a sound use of the resources we share as a community.

Most healthcare extends lives and reduces suffering, but too much medicine remains unnecessary and harmful. Reducing medical excess is not primarily about saving money, it is about avoiding harm to people and the planet. We hope this podcast series will inspire listeners all over the world to imagine novel and radical approaches for a more sustainable healthcare, and to dare to move from imagination to action.

The Recovery is co-hosted by Fiona Godlee and Ray Moynihan, and available at https://sustainablehealthcare.cochrane.org/podcast-recovery

Please visit Cochrane Sustainable Healthcare's website for more information about the podcast and their work.

Competing interests: $\mathrm{M}$ J is a member of the Scientific Committee for the Preventing Overdiagnosis Conference. FG: As Editor in Chief, FG has led The BMJ's campaign on Too Much Medicine (https://www.bmj.com/too-muchmedicine), and overseen the journal's series of articles on Overdiagnosis (https://www.bmj.com/specialties/too-much-medicine) and other content aiming to address the issue of medical overuse. She is an Ambassador for the UK. Health Alliance on Climate Change, a Trustee of the Eden Project, and a member of the 


\section{OPINION}

Board of the Preventing Overdiagnosis Conference. These roles are unremunerated. RM is an adjunct associate professor at the University of Sydney. He has co-hosted The Recommended Dose podcast, produced by Cochrane Australia, and co-promoted by The BMJ. He is a founder of the Preventing Overdiagnosis conference.

Provenance and peer review: Commissioned, not peer reviewed

1 OECD. Tackling Wasteful Spending on Health. OECD Publishing, 2017, doi: 10.1787/9789264266414-

2 Welch HG, Schwartz L, Woloshin S. Overdiagnosed: Making People Sick in the Pursuit of Health Beacon Press, 2011

3 Cotter AR, Vuong K, Mustelin L, etal. Do psychological harms result from being labelled with an unexpected diagnosis of abdominal aortic aneurysm or prostate cancer through screening? A systematic review. BMJ Open 2017;7:e017565.

doi: 10.1136/bmjopen-2017-017565. pmid: 29237653

4 May C, Montori VM, Mair FS. We need minimally disruptive medicine. BMJ 2009;339:b2803. doi: 10.1136/bmj.b2803. pmid: 19671932

5 Glasziou P, Straus S, Brownlee S, etal. Evidence for underuse of effective medical services around the world. Lancet 2017;390:169-77. doi: 10.1016/S0140-6736(16)30946-1. pmid: 28077232

6 Marmot M, Allen J, Bell R, Bloomer E, Goldblatt PConsortium for the European Review of Social Determinants of Health and the Health Divide. WHO European review of social determinants of health and the health divide. Lancet 2012;380:1011-29. doi: 10.1016/S0140-6736(12)61228-8. pmid: 22964159

7 Barratt A, McGain F. Overdiagnosis is increasing the carbon footprint of healthcare. BMJ 2021;375:n2407. doi: 10.1136/bmj.n2407. pmid: 34607810

8 Pathirana T, Clark J, Moynihan R. Mapping the drivers of overdiagnosis to potential solutions. BMJ2017;358:j3879. doi: 10.1136/bmj.j3879. pmid: 28814436

9 Johansson M, Bero L, Bonfill X, etal. Cochrane Sustainable Healthcare: evidence for action on too much medicine. Cochrane Database Syst Rev 2019;12:ED000143. doi: 10.1002/14651858.ED000143 pmid: 31808554

10 Petursson H, Getz L, Sigurdsson JA, Hetlevik I. Current European guidelines for management of arterial hypertension: are they adequate for use in primary care? Modelling study based on the Norwegian HUNT 2 population. BMC Fam Pract 2009;10:70

doi: 10.1186/1471-2296-10-70. pmid: 19878542 